\title{
Changes in water use efficiency and driving forces of the karst vegetation ecosystem in Southwest China
}

\section{Xinyu Shi}

China University of Mining and Technology Beijing Campus

\section{Shuang Bai}

China University of Mining and Technology Beijing Campus

Wei Chen ( $\sim$ chenw@cumtb.edu.cn )

China University of Mining Technology: China University of Mining and Technology https://orcid.org/0000-0002-2585-9984

\section{Research Article}

Keywords: WUE, climate change, human activity, Karst region of Southwest China

Posted Date: February 16th, 2022

DOI: https://doi.org/10.21203/rs.3.rs-1309001/v1

License: (a) (1) This work is licensed under a Creative Commons Attribution 4.0 International License. Read Full License 
2 Changes in the water use efficiency and driving forces of the karst

\title{
vegetation ecosystem in Southwest China
}

Xinyu Shi a , Shuang Bai ${ }^{\text {a }}$, Wei Chen ${ }^{\text {a,* }}$

${ }^{a}$ College of Geoscience and Surveying Engineering, China University of Mining \& Technology, Beijing 100083, China

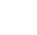

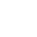

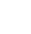

10

11

\section{Corresponding author}

Wei Chen

\begin{abstract}
College of Geoscience and Surveying Engineering, China University of Mining
\end{abstract} \& Technology, Beijing 100083, China

Telephone: +86-138-1195-0643

Email: chenw@cumtb.edu.cn

Submitted for publication in

Environmental Science and Pollution Research 
Abstract: As the largest contiguous karst area of China, the southwestern karst area is a typical ecologically fragile area affecting local vegetation dynamics. Ecosystem water use efficiency (WUE) is an important factor outlining the vegetation's ability to produce organic matter with a limited water supply. Therefore, it is important to determine WUE variation trends in this ecologically fragile region. In this paper, we used MODIS remote sensing datasets, meteorological data and land cover data to analyze the spatiotemporal changes in vegetation water use efficiency in the southwest karst region from 2001 to 2017 . We also further quantitatively analyzed the impact of climate change and human activities on the spatial and temporal patterns of vegetation WUE in the study area. The main conclusions were as follows. (1) From 2001 to 2017, in terms of temporal characteristics, the interannual variation in WUE fluctuated greatly, ranging from 1.33 to $1.51 \mathrm{~g} \mathrm{C}$ $\mathrm{kg}^{-1} \mathrm{H}_{2} \mathrm{O}$, with a multiyear average of $1.43 \mathrm{~g} \mathrm{C} \mathrm{kg}^{-1} \mathrm{H}_{2} \mathrm{O}$ and an average rate of change of -0.0046 $\mathrm{g} \mathrm{C} \mathrm{kg}^{-1} \mathrm{H}_{2} \mathrm{O} \mathrm{yr}{ }^{-1}$. In terms of spatial characteristics, areas with a higher WUE were concentrated in central Sichuan and northeastern Yunnan. (2) There were also certain differences in the WUE for different vegetation types. The annual average WUE of each vegetation type decreased in the following order: evergreen coniferous forest $>$ evergreen broad-leaved forest $>$ mixed forest $>$ deciduous broad-leaved forest $>$ cultivated land $>$ deciduous coniferous forest $>$ grassland $>$ cultivated land and natural vegetation> shrub forest. (3) The vegetation WUE of $70.66 \%$ in this area was positively correlated with temperature. Additionally, $79.68 \%$ of the vegetation WUE was negatively correlated with precipitation. The relative contribution rates of climate change and human activities to the change trend in WUE were $15 \%$ and $85 \%$, respectively. These results provide scientific support for local vegetation restoration and protection policies.

Key Words: WUE, climate change, human activity, Karst region of Southwest China

\section{Introduction}

The global carbon-water cycle system is affected by global warming to a certain extent. The carbon cycle refers to the phenomenon that carbon elements are affected by anthropogenic or natural factors during the exchange and migration in the various layers of the Earth and cyclically follow the Earth's movement (Cheng et al., 2017; Qiu et al., 2018). In terrestrial ecosystems, green vegetation mainly uses its own photosynthesis to absorb $\mathrm{CO}_{2}$ symbiotic from the atmosphere to sequester carbon and then participates in the global carbon cycle process where it plays an irreplaceable role (Baldocchi, 2008; Hofhansl et al., 2020). The carbon cycle and water cycle are 
matter mass produced by vegetation consumption per unit mass of water in the ecosystem; furthermore, it is one of the important indicators used to judge the degree of mutual influence of the carbon-water cycle system (Xue et al., 2015a).

The southwest karst area is not only the largest contiguous karst area in China but also a typical ecologically fragile area (Lakshmi Kumar et al., 2016; Wang et al., 2021). The problem of the ecological environment seriously restricts economic development and the construction of ecological civilization in the southwest karst area. In recent years, the Chinese government has initiated a series of ecological restoration projects in response to frequent ecological and environmental problems, for example: returning farmland to forest (grass), closing hills for greening, substituting grain for food, individual contracting, etc. Although ecological restoration has progressed, ecological problems such as rocky desertification are still severe (Qi et al., 2013; Zhou et al., 2018). Therefore, exploring the ecosystem carbon-water cycle and its influencing factors in the southwest karst area is still a key issue in promoting ecological restoration in the southwest karst area. Moreover, investigating the temporal and spatial changes in WUE, the impact mechanism of climate change on WUE and the quantification of the relative contribution rate will help deepen our understanding of the geo-atmospheric system and terrestrial ecosystem in the southwest karst region, and the ecological civilization of the southwest karst region. The promotion of construction and economic development in this region is of great significance.

There has been much domestic and foreign research about ecosystem WUE in recent years, and in different periods, the research objects, scales and methods of WUE have differed. Initial studies mostly focused on the leaf scale or individual level of vegetation, and the methods were mostly measurements and investigations (Condon et al., 2004). With the development of WUE, the research scale has developed to the canopy level, and the research methods are also commonly used in vorticity correlation techniques ( $\mathrm{Li}$ et al., 2015). Small-scale WUE research is expensive and hard to implement in large areas. Therefore, simulation methods based on remote sensing models and satellite remote sensing data products have gradually developed and are widely used in large-scale WUE research. Ecosystem WUE changes are affected by climatic factors, and changes in climatic factors such as temperature and precipitation have different impacts on ecosystem WUE (Ahmadi et al., 2019).

In summary, the current research on WUE is mostly focused on exploring the response of 
climate change to ecosystem WUE, and research on climate change in the ecologically fragile karst areas in southwestern China is relatively scarce. Climate change and vegetation factors are the main factors that affect ecosystem WUE. Therefore, clarifying the mechanism of their impact on the WUE of the ecosystem can provide a scientific basis for the construction of ecological civilization in the southwest karst region. We explored the spatiotemporal characteristics of WUE in the southwest karst region. The objectives were to (1) explore the spatial and temporal characteristics of WUE using long-term remote sensing dataset, and (2) analyze the influence of vegetation factors, climate change, and human activities on the spatial distribution pattern of WUE. This study evaluates the results of restoration projects and provides critical advice to the government to manage the ecologically fragile karst region. Moreover, it can help to better understand the carb cycle in the karst region and its driving factors.

\section{Materials and methods}

\subsection{Data}

\subsubsection{Study area}

The karst area of Southwest China is between $20^{\circ} \sim 35^{\circ} \mathrm{N}$ and $97^{\circ} \sim 118^{\circ} \mathrm{E}$, which is the largest contiguous schist karst area in the country and one of the three continuous karst areas in the world, as shown in Fig. 1 (Jiang et al., 2014a; Wang et al., 2004). The region consists of 8 provinces (cities, autonomous regions): Sichuan, Chongqing, Hubei, Hunan, Yunnan, Guizhou, Guangxi, and Guangdong. The land area of the whole region is approximately $1,937,400 \mathrm{~km}^{2}$, accounting for $20.09 \%$ of the country's land area, of which the karst area accounts for approximately $26.51 \%$ of the total area of the region (Cao et al., 2015; Jiang et al., 2014b). The average elevation of this area is $1283 \mathrm{~m}$, the terrain slopes from northwest to southeast (Wang et al., 2018), and the climate is warm and humid in most areas, with rich vegetation types. 


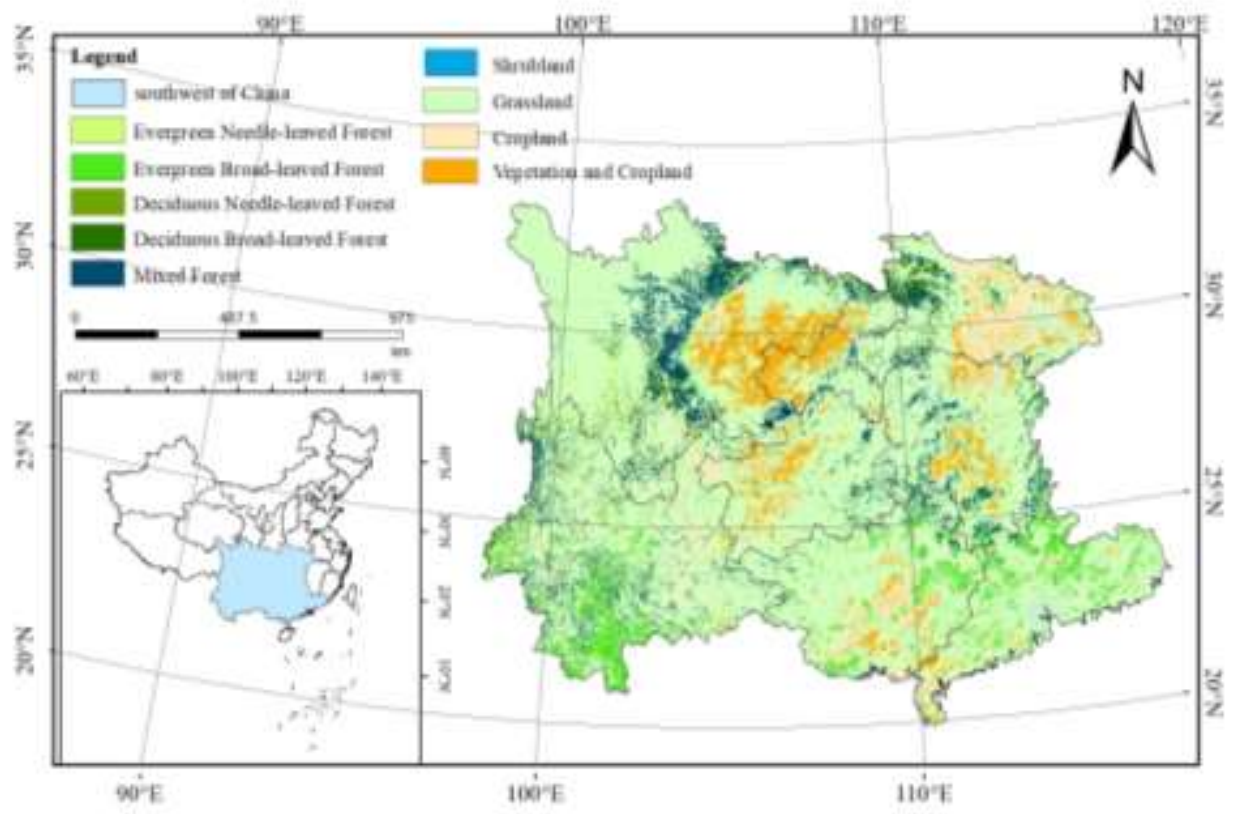

Fig. 1 Geographical Location and Main Vegetation Distribution in Southwest Karst Region

\subsubsection{Data}

In this study, the Moderate-Resolution Imaging Spectroradiometer (MODIS) gross primary production (GPP) and evapotranspiration (ET) datasets from 2001 to 2017, with spatial resolutions of $500 \mathrm{~m}$ and temporal resolutions of 8 days, were adopted to calculate WUE. MODIS GPP provides a near real-time estimate of the global GPP, and verification based on the eddy covariance (EC) flux measurement method shows that it has a certain degree of reliability in China (Verma et al., 2014; Zhu et al., 2016). The algorithm used in MODIS ET products is based on the logic of the PenmanMonteith equation and has been verified to have a relatively reliable accuracy. Thus, this method has been widely used in global and regional research (Mu et al., 2011; Mueller et al., 2011; Zhao et al., 2006).

The MODIS normalized difference vegetation index (NDVI) datasets with a spatial resolution of $250 \mathrm{~m}$ and a temporal resolution of 16 days were provided by NASA Earth Data (https://earthdata.nasa.gov/), and the NDVI interannual data were synthesized using the commonly used maximum value composite (MVC) method. The land cover data were the MCD12Q1 data product from the NASA Earth Data, with a spatial resolution of $500 \mathrm{~m}$. This study reclassified 17 land use types into 9 planting coverage categories based on the international geosphere-biosphere programmer (IGBP) classification scheme, as shown in Fig. 1. Meteorological data mainly included temperature and precipitation. These datasets were developed by Peng et al. (Peng et al., 2019) 
based on the Delta spatial downscaling scheme with a spatial resolution of $0.5^{\prime}$, and were verified by using data with a reliable accuracy from 496 independent meteorological observation points.

\subsection{Methods}

\subsubsection{Calculation of WUE}

This study used the calculation method of WUE based on GPP and ET, and the calculation formula is as follows:

$$
\mathrm{WUE}=\mathrm{GPP} / \mathrm{ET}
$$

\subsubsection{Trend analytical methods}

Trend analysis is a method to show the interannual variation of data and it has many calculation methods, including empirical mode decomposition (emd) and linear trend analysis. In this study, Theil-Sen was used as it is a robust, nonparametric statistical trend calculation method. This method has a high computational efficiency, is insensitive to measurement errors and outlier data, and is often used in trend analysis of long-term series data.

Theil-Sen regression is a nonparametric slope estimation method (Liu et al., 2019). The MannKendall test is a nonparametric hypothesis test. Theil-Sen slope estimation combined with the Mann-Kendall test method provides reliable results for trend analysis and significance testing of long-term series data and has been commonly used in research fields such as vegetation remote sensing monitoring and meteorology (Wu et al., 2014).

The slope calculation formula of Theil-Sen is as follows:

$$
\beta=\operatorname{Median}\left(\frac{x_{j}-x_{i}}{j-i}\right), \forall j>i
$$

where $\beta$ represents the change trend of the time series, the positive and negative values of $\beta$ represent the rises and falls of the time series, respectively, $\mathrm{n}$ is the number of elements in this time series and $0<\mathrm{i}<\mathrm{j}<\mathrm{n}$, and $x_{i}$ and $x_{j}$ represent the WUE values of the $\mathrm{i}^{\text {th }}$ year and $\mathrm{j}^{\text {th }}$ year, respectively.

The process of the Mann-Kendall trend test method is as follows: For the time series $X\left\{\mathrm{x}_{1}, \mathrm{x}_{2} \ldots \mathrm{x}_{\mathrm{n}}\right\}$, the test statistic $\mathrm{S}$ is as follows:

$$
S=\sum_{i=1}^{n-1} \sum_{j=i+1}^{n} \operatorname{sgn}\left(x_{j}-x_{i}\right)
$$




$$
\operatorname{sgn}\left(x_{j}-x_{i}\right)=\left\{\begin{array}{c}
1, x_{j}-x_{i}>0 \\
0, x_{j}-x_{i}=0 \\
-1, x_{j}-x_{i}<0
\end{array}\right.
$$

Where $x_{i}$ and $x_{j}$ represent the WUE values of the $\mathrm{i}^{\text {th }}$ year and $\mathrm{j}^{\text {th }}$ year, respectively.

The statistics of Mann-Kendall trend test are as follows:

$$
\begin{gathered}
\mathrm{Z}=\left\{\begin{array}{l}
\frac{S-1}{\sqrt{\operatorname{VAR}(S)}}, S>0 \\
0, S=0 \\
\frac{S+1}{\sqrt{\operatorname{VAR}(S)}}, S<0
\end{array}\right. \\
\operatorname{VAR}(S)=\left(n(n-1)(2 n+5)-\sum_{i=1}^{m} t_{i}\left(t_{i}-1\right)\left(2 t_{i}+5\right)\right) / 18
\end{gathered}
$$

where $n$ is the number of elements in this time series, $m$ is the number of repeated data in this time series, and $t_{i}$ is the number of duplicates in group $i$. For a given significance level of $\alpha(0.05)$, if the value of $|Z|>Z_{1-\frac{\alpha}{2}}$, it means the increasing or decreasing trend of the time series is significant; otherwise, the variation trend is statistically insignificant.

\subsubsection{Hurst exponent}

The Hurst exponent based on rescaled range analysis $(\mathrm{R} / \mathrm{S})$ is usually used to judge the sustainability of a time series. At present, the index has been widely used in various research fields, such as meteorological research and vegetation monitoring (Xu et al., 2018). The Hurst exponent is referred to as the "index of dependence" or "index of long-range dependence". It quantifies the relative tendency of a time series either to regress strongly to the mean or to cluster in a certain direction. This study uses this index to analyze the sustainability of future change trends of the vegetation WUE in the southwest karst area. The major procedure used to calculate the Hurst exponent in this study was as follows (Jiang et al., 2015):

(1) Obtain the annual average WUE time series:

$$
\operatorname{WUE}(t), t=1,2, \cdots, n
$$

Where $t$ is the number of elements in this time series, $0<\mathrm{t}<\mathrm{n}$.

(2) Calculate the average WUE over the time range:

$$
\langle\operatorname{WUE}\rangle_{\tau}=\frac{1}{\tau} \sum_{t=1}^{\tau} \operatorname{WUE}(t) \quad \tau=1,2, \cdots, n
$$

(3) Calculate the accumulated deviation of WUE over the time range: 


$$
X_{(t, \tau)}=\sum_{t=1}^{t}\left(\operatorname{WUE}(t)-\langle\mathrm{WUE}\rangle_{\tau}\right) \quad 1 \leq t \leq \tau
$$

(4) Create the range sequence $R_{(\tau)}$ :

$$
R_{(\tau)}=\max _{1 \leq t \leq \tau} X_{(t, \tau)}-\min _{1 \leq t \leq \tau} X_{(t, \tau)} \quad \tau=1,2, \cdots, n
$$

(5) Create the standard deviation sequence $S_{(\tau)}$ :

$$
S_{(\tau)}=\left[\frac{1}{\tau} \sum_{t=1}^{\tau}\left(\operatorname{WUE}(t)-\langle\operatorname{WUE}\rangle_{\tau}\right)^{2}\right]^{\frac{1}{2}} \tau=1,2, \cdots, n
$$

(6) Calculate the Hurst exponent:

$$
\frac{R_{(\tau)}}{S_{(\tau)}}=(c \tau)^{H}
$$

where $\mathrm{H}$ is the Hurst exponent; when $0<\mathrm{H}<0.5$, the time series has a trend of anti-continuity in the future, and when $0.5<\mathrm{H}<1$, the time series has positive sustainability.

\subsubsection{Correlation analysis}

Correlation analysis refers to the statistical analysis of two or more variable elements that have a certain correlation to judge the close degree of correlation between variables (Tong et al., 2016). In this study, we used Person's correlation coefficient to measure the correlation between WUE and climate factors, which was matched with continuous data and a linear relationship.

The calculation formula of the correlation coefficient is as follows:

$$
R_{x y}=\frac{\sum_{i=1}^{n}\left(x_{i}-\bar{x}\right)\left(y_{i}-\bar{y}\right)}{\sqrt{\sum_{i=1}^{n}\left(x_{i}-\bar{x}\right)^{2}} \sqrt{\sum_{i=1}^{n}\left(y_{i}-\bar{y}\right)^{2}}}
$$

Where $\mathrm{x}$ represents the WUE, $y$ is the climate factor (precipitation or temperature), $n$ is the number of samples, and $\bar{x}, \bar{y}$ are the mean values of the WUE and climate factor for $\mathrm{n}$ years, respectively.

t-test was adopted as follows:

$$
1=\frac{R_{x y} \sqrt{n-2}}{1-R_{x y}^{2}}
$$

where $\mathrm{R}_{\mathrm{xy}}$ is the Pearson coefficient. When $\mathrm{R}_{\mathrm{xy}}<0$, the correlation is negative; otherwise, it is positive.

\subsubsection{Residual analysis}


The residual analysis method is used to quantify the impact of influencing factors on WUE,

193 and the method has been widely used in remote sensing applications and other research fields. The

194 influence of climatic factors and human activities on the water use efficiency of vegetation in the southwest karst area is distinguished. In this paper, the residual analysis method is used to quantify the influence of these two factors on water use efficiency. The calculation formula of the residual analysis is as follows:

$$
\begin{aligned}
& W U E_{\text {human }}=W U E_{\text {obs }}-W U E_{\text {pre }} \\
& W U E_{\text {pre }}=a * T e m+b * \text { Pre }+c
\end{aligned}
$$

where $W E_{\text {human }}$ is the water use efficiency caused by human activities; $W_{\text {obs }}$ is the observed water use efficiency, that is, the water use efficiency calculated by GPP and ET; WUE pre is the water use efficiency simulated by the WUE climate regression model; Tem and Pre are the average annual temperature and annual precipitation, respectively; and a, b, and c are the coefficients of the WUE climate regression model.

\subsubsection{Relative contribution rate}

This study classified the WUE change trend degree under the influence of climate factors and human activities (Table 1). The relative contribution of factors influencing WUE in the southwest karst area was calculated (Table 2).

Table 1 Impact grading of climatic factors and human activities on WUE in karst areas of 208 Southwest China

\begin{tabular}{cc}
\hline S $(\text { WUE })^{*}$ & Level \\
\hline$<-0.015$ & Significant inhibition \\
$-0.015 \sim-0.010$ & Moderate inhibition \\
$-0.010 \sim-0.005$ & Slight inhibition \\
$-0.005 \sim 0.005$ & Almost no effect \\
$0.005 \sim 0.010$ & Slight promotion \\
$0.010 \sim 0.015$ & Moderate promotion \\
$>0.015$ & Significant promotion \\
\hline
\end{tabular}

210 factors or human activities, namely, $\mathrm{S}\left(\mathrm{WUE}_{\mathrm{Pre}}\right)$ and $\mathrm{S}\left(\mathrm{WUE}_{\text {human }}\right)$.

211 Table 2 The influencing factors of WUE and the calculation standard of the relative contribution

212 rate in the karst area of Southwest China

\begin{tabular}{ccccc}
\hline \multirow{2}{*}{$\mathrm{S}\left(\mathrm{WUE}_{\mathrm{obs}}\right)$} & \multicolumn{2}{c}{ Influencing factor trend } & \multicolumn{2}{c}{ Relative contribution rate of influencing factors } \\
\cline { 2 - 5 } & $\mathrm{S}\left(\mathrm{WUE}_{\text {pre }}\right)$ & $\mathrm{S}\left(\mathrm{WUE}_{\text {human }}\right)$ & Pre & Human activities \\
& $>0$ & $>0$ & $\frac{\mathrm{S}\left(\mathrm{WUE}_{\text {pre }}\right)}{\mathrm{S}\left(\mathrm{WUE}_{\text {obs }}\right)}$ & $\frac{\mathrm{S}\left(\mathrm{WUE}_{\text {human }}\right)}{\mathrm{S}\left(\mathrm{WUE}_{\text {obs }}\right)}$ \\
$>0$ & $>0$ & $<0$ & 100 & 0 \\
& $<0$ & $>0$ & 0 & 100 \\
\hline
\end{tabular}




\begin{tabular}{ccccc}
\hline$<0$ & $<0$ & $<0$ & $\frac{\mathrm{S}\left(\mathrm{WUE}_{\text {pre }}\right)}{\mathrm{S}\left(\mathrm{WUE}_{\text {obs }}\right)}$ & $\frac{\text { slope}\left(\mathrm{WUE}_{\text {human }}\right)}{\text { slope }\left(\mathrm{WUE}_{\text {obs }}\right)}$ \\
& $<0$ & $>0$ & 100 & 0 \\
& $>0$ & $<0$ & 0 & 100 \\
\hline
\end{tabular}

213

\section{Results}

\subsection{Spatial distribution characteristics of WUE}

\subsubsection{Spatial distribution of WUE}

Fig. 2 demonstrates that there are large spatial heterogeneities for WUE. As the WUE is affected by both GPP and ET, it is essential to show the spatial distributions of GPP and ET. The average annual GPP from 2001 to 2017 showed a decreasing trend from east to west and from south to north; furthermore, the average annual ET from 2001 to 2017 showed a decreasing trend from southeast to northwest, as shown in Fig. 3. The average annual WUE of the southwest terrestrial ecosystem from 2001 to 2017 was $1.43 \mathrm{~g} \mathrm{C} \mathrm{kg}^{-1} \mathrm{H}_{2} \mathrm{O}$, and the value range was $0-3.43 \mathrm{~g} \mathrm{C} \mathrm{kg}^{-1} \mathrm{H}_{2} \mathrm{O}$. The high value of WUE in the southwest karst region was mainly distributed in Yunnan Province, parts of Guangdong Province, northwestern Hubei Province, and northeastern Sichuan Province; the low-value areas were concentrated in western Sichuan Province. The average annual GPP was $1059.84 \mathrm{~g} \mathrm{C} \mathrm{m}^{-2} \mathrm{yr}^{-1}$, and the value range was $0 \sim 2938.22 \mathrm{~g} \mathrm{C} \mathrm{m}^{-2} \mathrm{yr}^{-1}$. The average annual ET of the southwest terrestrial ecosystem was $733.18 \mathrm{~mm} \mathrm{yr}^{-1}$, and the value range was $0 \sim 1761.76 \mathrm{~mm} \mathrm{yr}^{-1}$. 


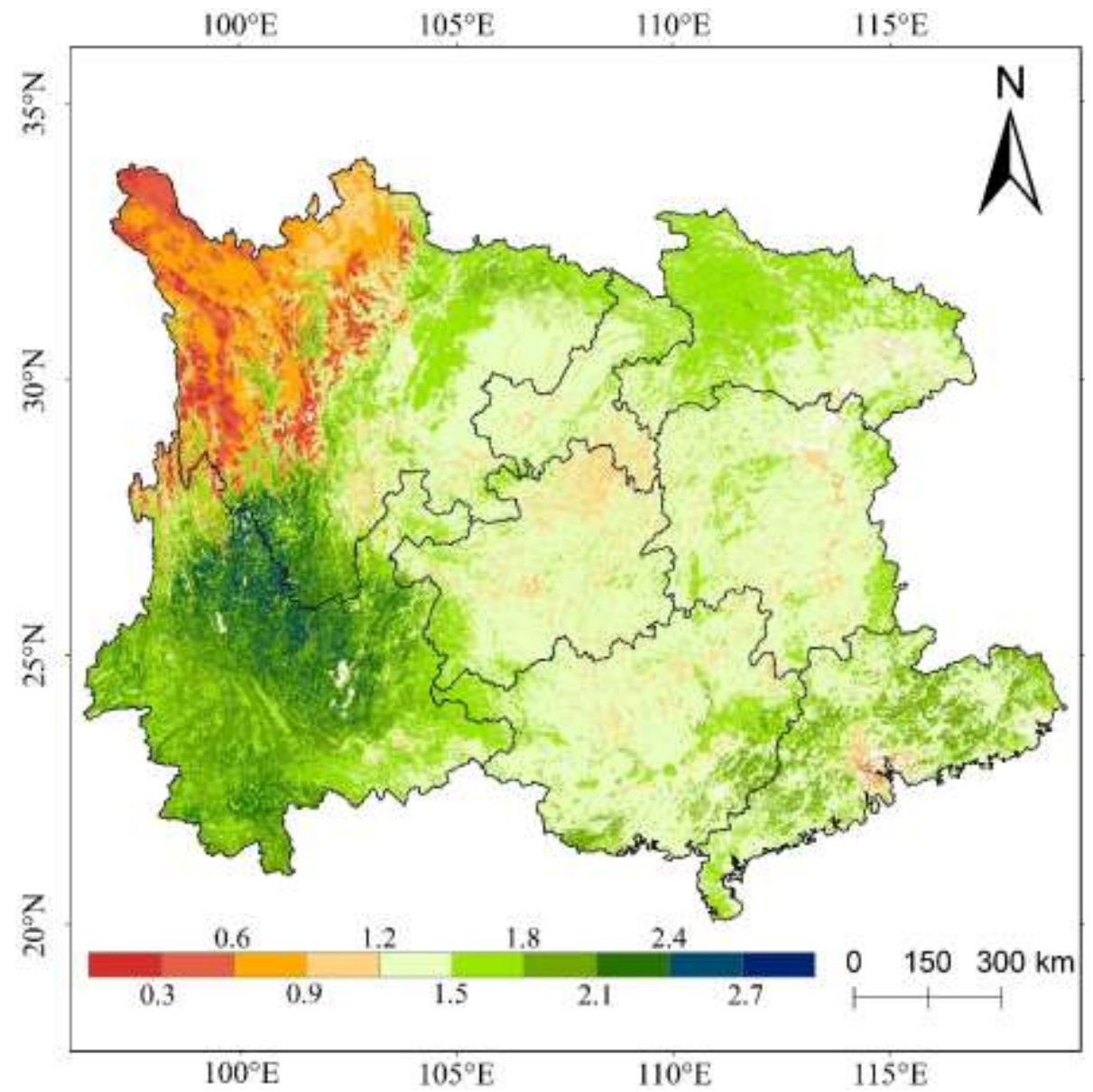

230 Fig. 2 Spatial distribution of annual mean WUE vegetation ecosystem in the karst regions of
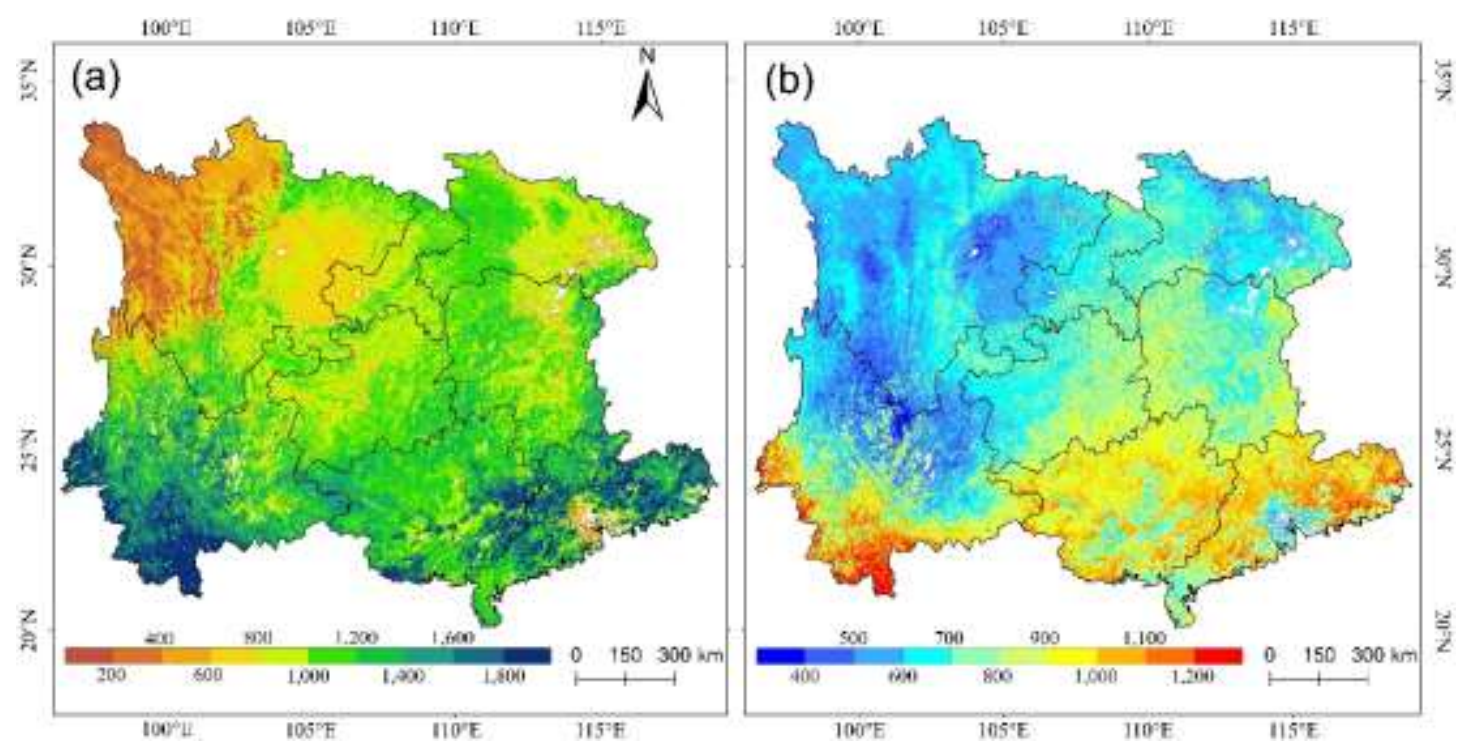

Fig. 3 Spatial distribution of annual mean GPP (a) $\left(\mathrm{g} \mathrm{C} \mathrm{m}^{-2} \mathrm{yr}^{-1}\right)$ and ET (b) $\left(\mathrm{mm} \mathrm{yr}^{-1}\right)$ in the karst regions vegetation ecosystem of Southwest China during 2001 2017 
Due to the differences in carbon sequestration and water consumption, different vegetation types also have certain differences in WUE. The annual average WUE of evergreen coniferous forests was the highest from 2001 2017, reaching $1.73 \mathrm{~g} \mathrm{C} \mathrm{kg}^{-1} \mathrm{H}_{2} \mathrm{O}$, as shown in Fig. 4. The annual average WUE of evergreen broad-leaved forest was approximately $1.70 \mathrm{~g} \mathrm{C} \mathrm{kg}^{-1} \mathrm{H}_{2} \mathrm{O}$, and its annual average GPP and annual average ET values were both the highest, with values of $1854.50 \mathrm{~g} \mathrm{C} \mathrm{m}^{-2}$ $\mathrm{yr}^{-1}$ and $1026.91 \mathrm{~mm} \mathrm{yr}^{-1}$, respectively. The annual average WUE of shrubs was the lowest, at only $1.25 \mathrm{~g} \mathrm{C} \mathrm{kg}^{-1} \mathrm{H}_{2} \mathrm{O}$. The annual average GPP and annual average ET were $634.35 \mathrm{~g} \mathrm{C} \mathrm{m}^{-2} \mathrm{yr}^{-1}$ and $511.11 \mathrm{~mm} \mathrm{yr}^{-1}$, respectively. From 2001 to 2017 , the annual average WUE of each vegetation type decreased in the order of evergreen coniferous forest $\left(1.73 \mathrm{~g} \mathrm{C} \mathrm{kg}^{-1} \mathrm{H}_{2} \mathrm{O}\right)>$ evergreen broad-leaved forest $\left(1.70 \mathrm{~g} \mathrm{C} \mathrm{kg}^{-1} \mathrm{H}_{2} \mathrm{O}\right)>$ mixed forest $\left(1.54 \mathrm{~g} \mathrm{C} \mathrm{kg}^{-1} \mathrm{H}_{2} \mathrm{O}\right)>$ deciduous broad-leaved forest $(1.45$ $\left.\mathrm{g} \mathrm{C} \mathrm{kg}^{-1} \mathrm{H}_{2} \mathrm{O}\right)>$ cultivated land $\left(1.42 \mathrm{~g} \mathrm{C} \mathrm{kg}^{-1} \mathrm{H}_{2} \mathrm{O}\right)>$ deciduous coniferous forest $\left(1.35 \mathrm{~g} \mathrm{C} \mathrm{kg}^{-1}\right.$ $\left.\mathrm{H}_{2} \mathrm{O}\right)>$ grassland $\left(1.32 \mathrm{~g} \mathrm{C} \mathrm{kg}^{-1} \mathrm{H}_{2} \mathrm{O}\right)>$ cultivated land and natural vegetation $\left(1.30 \mathrm{~g} \mathrm{C} \mathrm{kg}^{-1} \mathrm{H}_{2} \mathrm{O}\right)>$ shrub forest $\left(1.25 \mathrm{~g} \mathrm{C} \mathrm{kg}^{-1} \mathrm{H}_{2} \mathrm{O}\right)$.

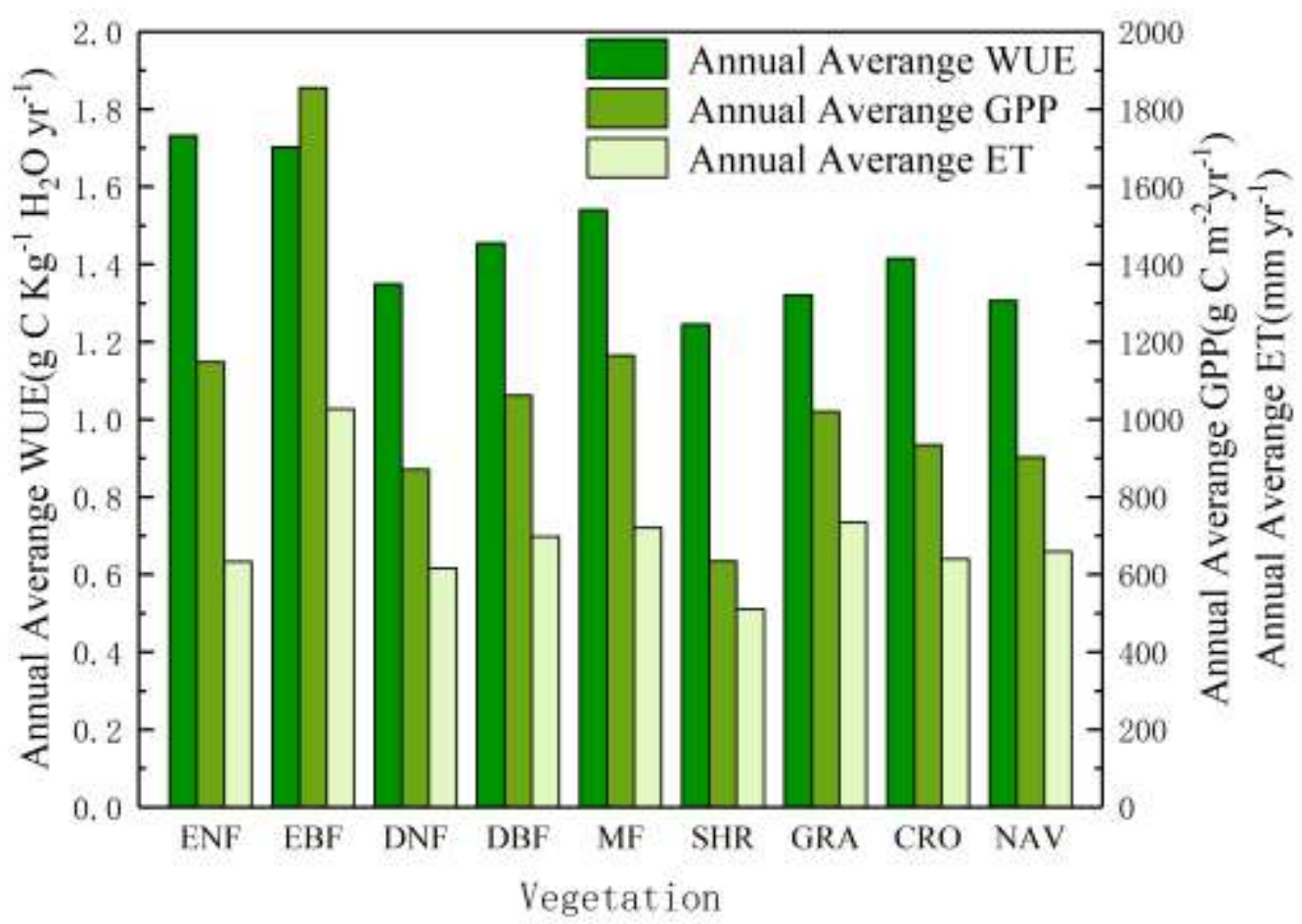

Fig. 4 Annual WUE annual GPP and annual ET of different vegetation types during 2001 2017 (ENF: evergreen coniferous forest, EBF: evergreen broad-leaved forest, DNF: deciduous coniferous forest, DBF: deciduous broad-leaved forest, MF: mixed forest, SHR: shrub, GRA: grassland, CRO: arable land, NAV: arable land and natural vegetation) 


\subsection{Interannual change trend of WUE}

258

259

260

261

262

263

\subsubsection{Temporal variation in WUE}

The interannual variation in the WUE of the terrestrial ecosystem in the southwest karst region fluctuated greatly, ranging from 1.33 to $1.51 \mathrm{~g} \mathrm{C} \mathrm{kg}^{-1} \mathrm{H}_{2} \mathrm{O}$, and the multiyear average was $1.43 \mathrm{C}$ $\mathrm{kg}^{-1} \mathrm{H}_{2} \mathrm{O}$. The WUE in the southwestern karst region from 2001 to 2017 generally decreased, while the GPP and ET both increased (S1). However, the relatively increasing trends of GPP were slightly lower than those of ET, causing the WUE to have an overall downward trend. From 2001 to 2017, the GPP fluctuated between 978.48 and $1162.54 \mathrm{~g} \mathrm{C} \mathrm{m}^{-2} \mathrm{yr}^{-1}$, and the multiyear average value was $1059.54 \mathrm{~g} \mathrm{C} \mathrm{m}^{-2} \mathrm{yr}^{-1}$. The range of ET varied from 654.51 to $822.22 \mathrm{~mm} \mathrm{yr}^{-1}$, and the multiyear average value was $733.18 \mathrm{~mm} \mathrm{yr}^{-1}$.

There were certain spatial differences in the annual average WUE from 2001 to 2017 in the southwest karst region, showing an overall decrease and a partial increase (Fig. 5). Areas with a significantly higher WUE were concentrated in central Sichuan and northeastern Yunnan, and most of the remaining areas showed a decreasing trend. This result was mainly due to the increase in GPP in central Sichuan and northeastern Yunnan but the decrease in some other areas and the increase in ET in most parts of the southwest (Fig. 6). From 2001 to 2017, the rate of change of WUE in Southwest China was between -0.13 and $0.12 \mathrm{~g} \mathrm{C} \mathrm{kg}^{-1} \mathrm{H}_{2} \mathrm{O} \mathrm{yr}$, and the average rate of change was close to zero, with a value of $-0.0046 \mathrm{~g} \mathrm{C} \mathrm{kg}^{-1} \mathrm{H}_{2} \mathrm{O} \mathrm{yr}$ (Fig. 5). The change trend of WUE was related to the change trend of GPP and ET. The range of GPP in the southwest karst region from 2001 to 2017 was $-123.86 \sim 151.73 \mathrm{~g} \mathrm{C} \mathrm{m}^{-2} \mathrm{yr}^{-1}$, and the average rate of change was $7.13 \mathrm{~g} \mathrm{C} \mathrm{m}^{-2} \mathrm{yr}^{-}$

${ }^{1}$ (Fig. 6a). In the past 17 years, ET in the southwestern karst region has shown an upward trend overall, with a rate of change ranging from -55.86 to $107.42 \mathrm{~mm} \mathrm{yr}^{-1}$ and an average rate of change of $7.59 \mathrm{~mm} \mathrm{yr}^{-1}$, which was slightly greater than the growth rate of GPP (Fig. 6b). 


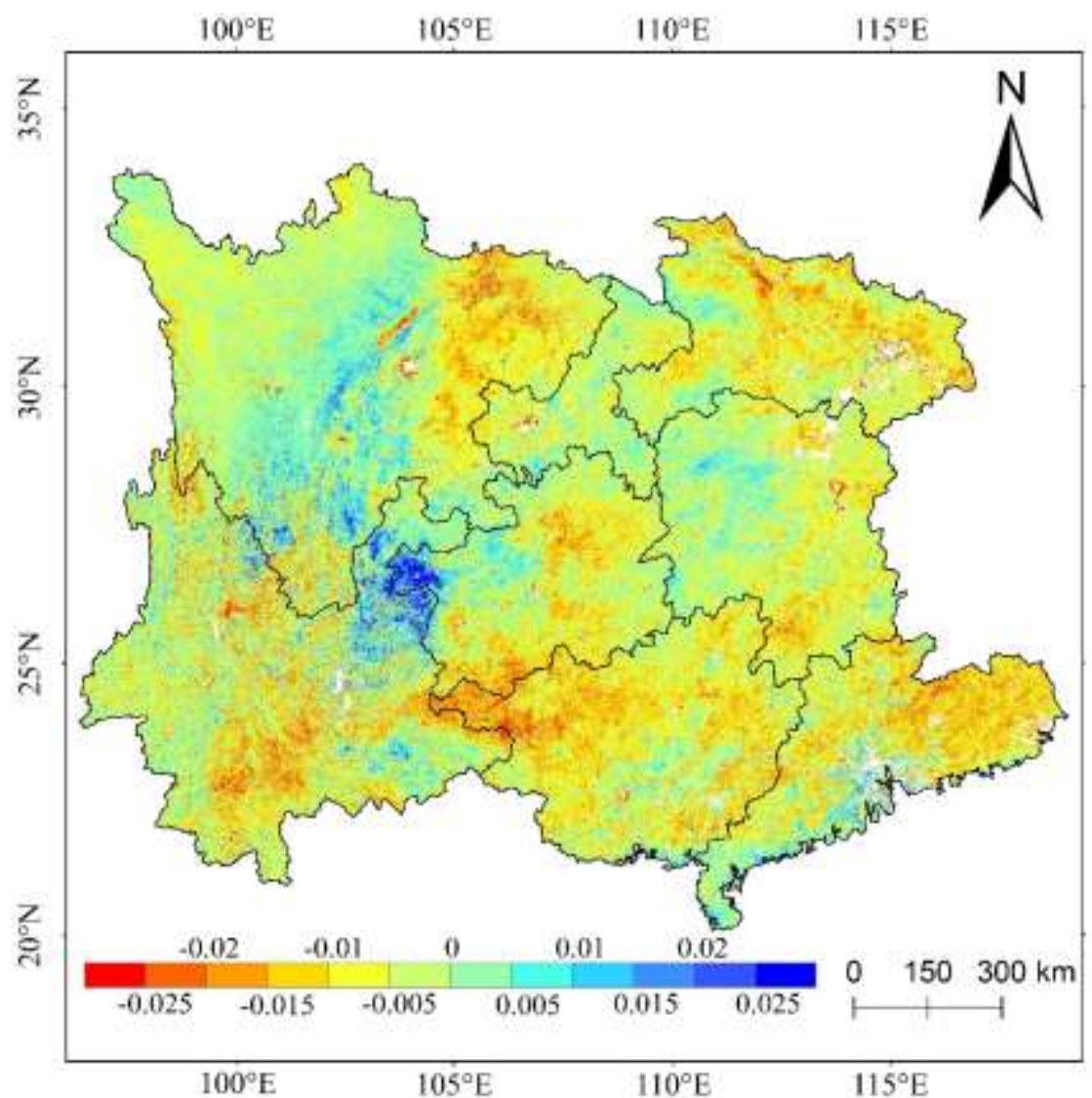

Fig. 5 Annual mean WUE change rate in the karst regions of Southwest China from 2001 to 2017 $\left(\mathrm{g} \mathrm{C} \mathrm{kg}^{-1} \mathrm{H}_{2} \mathrm{O} \mathrm{yr}^{-1}\right.$ )
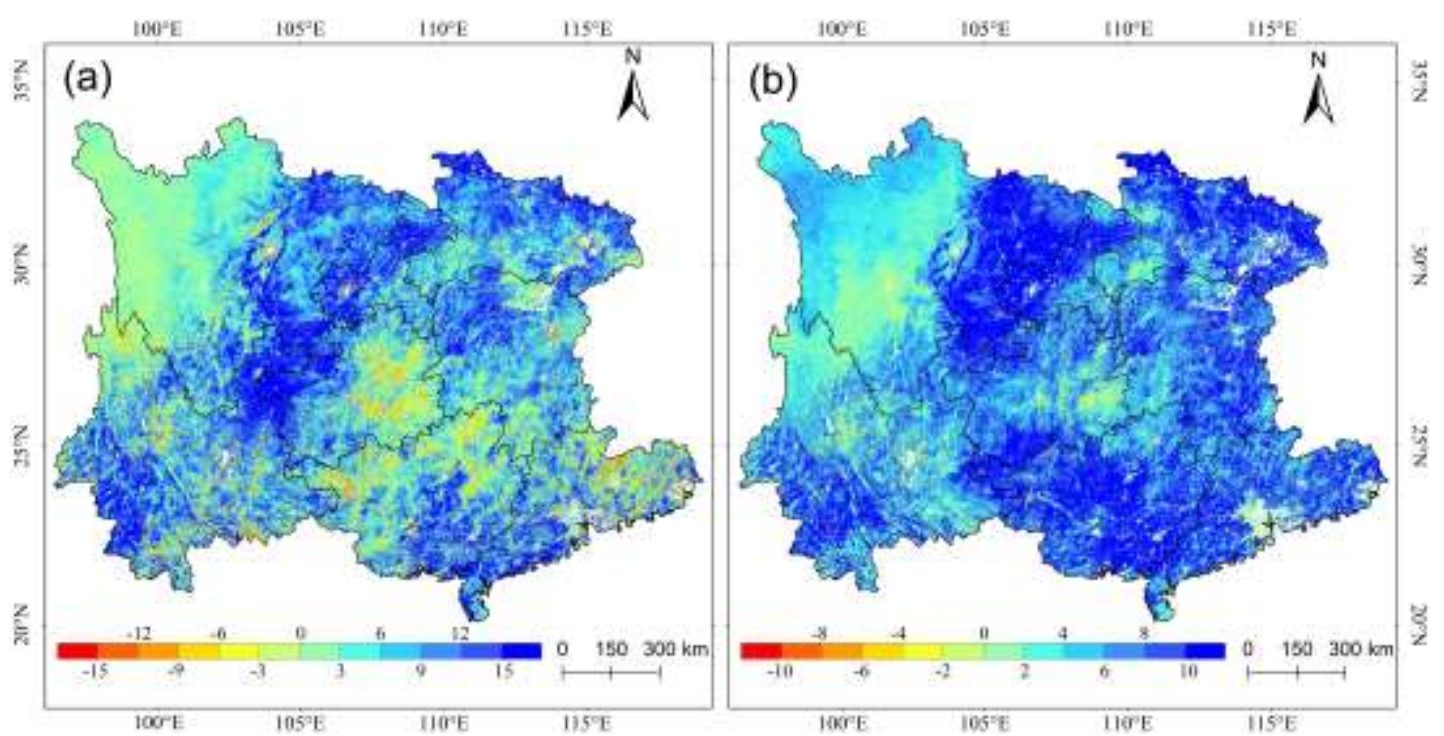

Fig. 6 Trends of annual average GPP (a) $\left(\mathrm{g} \mathrm{C} \mathrm{m}^{-2} \mathrm{yr}^{-1}\right)$ and ET (b) $\left(\mathrm{mm} \mathrm{yr}^{-1}\right)$ in the karst regions of Southwest China from 2001 to 2017

Table 3 shows that the trend analysis method of Sen+Mann-Kendall was used to calculate the change trends of WUE, GPP and ET in the southwest karst region from 2001 to 2017. From 2001 to $2017,71.59 \%$ of the regional WUE in the southwest karst region showed a downward trend (Fig.

7). Of this area, $11.24 \%$ of the region showed a significant decline, mainly distributed in Guangdong, 
Guangxi, western Yunnan and eastern Sichuan. The area of increase accounted for $28.41 \%$ of the

291 southwest karst area, of which only $1.87 \%$ of the area passed the significance test and was mainly

292 distributed in northeastern Yunnan, southern Sichuan, and western Guizhou. In the past 17 years,

293 both GPP and ET in the southwestern karst region have shown an overall upward trend and a partial

294 downward trend. A total of $83.61 \%$ of the GPP in the southwest karst region showed an upward

295 trend, and only $1.29 \%$ showed a significant downward trend. For ET, 95.6\% of the southwest karst

296 area showed an upward trend, and only $0.2 \%$ of the area showed a significant decline.

297 Table. 3 Trend analysis of annual mean WUE, GPP, and ET in the karst regions of Southwest

$298 \quad$ China in 2001 and 2017

\begin{tabular}{ccccc}
\hline & & WUE & GPP & ET \\
\cline { 3 - 5 } Trend & Degree & Percent $\%$ & Percent $\%$ & Percent $\%$ \\
\hline$\beta<0,|\mathrm{Z}|>1.96$ & Significant Degradation & 11.24 & 1.29 & 0.20 \\
$\beta \leq 0,|\mathrm{Z}| \leq 1.96$ & Slight Degradation & 60.35 & 15.10 & 4.20 \\
$\beta \geq 0,|\mathrm{Z}| \leq 1.96$ & Slight Improvement & 26.54 & 52.44 & 36.75 \\
$\beta>0,|\mathrm{Z}|>1.96$ & Significant Improvement & 1.87 & 31.17 & 58.85 \\
\hline
\end{tabular}

To reveal changes in trends and the sustainability of vegetation, the results obtained using

300 Theil-Sen trend analysis and the Mann-Kendall trend test were superimposed with the Hurst index results to generate coupled information about trend changes and sustainability (Fig. 7). The coupled results were divided into 5 categories: (1) sustainable and significant decrease, (2) sustainable and slight decrease, (3) sustainable and slight growth, (4) sustainable and significant growth, and (5)

304 uncertain changes. From 2001 to 2017, WUE had a sustainable and significant growth area accounting for $1.87 \%$, a sustainable and slight growth area accounting for $23.16 \%$, a sustainable and slight decline area accounting for $50.35 \%$, and a sustainable and significant decline area accounting for $11.07 \%$. In addition, $13.55 \%$ of the regional change trend was uncertain. 



Fig. 7 The significance analysis (a) and sustainability characteristics (b) of the annual average WUE change trend in the karst regions of Southwest China from 2001 to 2017

\subsubsection{WUE variations in different vegetation cover}

From 2001 to 2017, the average annual WUE of most vegetation types showed a downward trend (Fig. 8). The declines in evergreen broad-leaved forest and shrub forest were the most obvious, reaching a significance level of 0.05 , with decline rates of $-0.0115 \mathrm{~g} \mathrm{C} \mathrm{kg}^{-1} \mathrm{H}_{2} \mathrm{O} \mathrm{\textrm {yr } ^ { - 1 }}$ and $-0.0129 \mathrm{~g}$

$312 \mathrm{C} \mathrm{kg}^{-1} \mathrm{H}_{2} \mathrm{O} \mathrm{yr}{ }^{-1}$, respectively. In contrast, deciduous coniferous forests showed a significant upward 313 trend in the past 17 years $(\mathrm{P}<0.05)$, with a rate of increase of $0.0220 \mathrm{~g} \mathrm{C} \mathrm{kg}^{-1} \mathrm{H}_{2} \mathrm{O} \mathrm{yr}{ }^{-1}$. Evergreen

314 coniferous forests, deciduous broad-leaved forests, mixed forests, cultivated land, and cultivated 315 land and natural vegetation showed a downward trend in annual average WUE in the past 17 years, but the downward trend was not significant $(\mathrm{P}>0.05)$. 

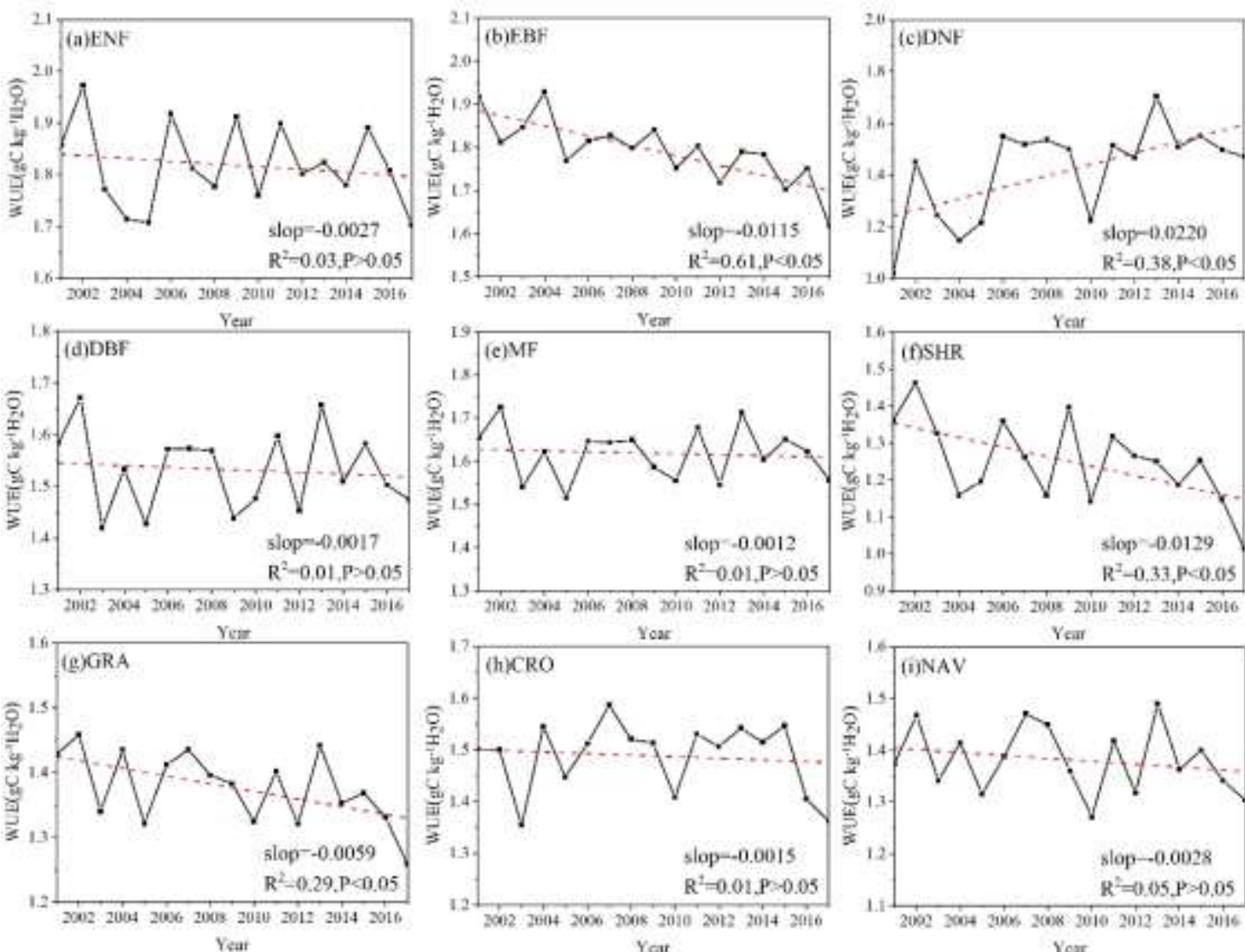

Fig. 8 Trends of annual average WUE of different vegetation types in the karst regions of Southwest China during 2001 2017 (ENF: evergreen coniferous forest, EBF: evergreen broadleaved forest, DNF: deciduous coniferous forest, DBF: deciduous broad-leaved forest, MF: mixed forest, SHR: shrub, GRA: grassland, CRO: arable land, NAV: arable land and natural vegetation)

\subsection{The influence of temperature and precipitation on the WUE trend}

Temperature and precipitation, as the main climatic factors, have an important impact on the spatial distribution of vegetation WUE. Therefore, the average annual temperature and annual precipitation were selected to evaluate the impact of climate change on the WUE changes in the terrestrial ecosystem in the southwest karst region from 2001 to 2017 . The vegetation WUE of $70.66 \%$ (as shown in Table 4) of the southwest karst area was positively correlated with temperature, and it was mainly distributed in the northwestern part of the southwest karst area. Fig. 9 and S2 show the partial correlation coefficient and its significance test of the annual temperature and precipitation and the average annual WUE in the southwest karst region from 2001 to 2017, respectively, and the proportion of areas where vegetation WUE was negatively correlated with precipitation accounted for $79.68 \%$ (as shown in Table 4). In the humid southwest karst region, precipitation was usually not the main limiting factor affecting vegetation growth. 
Table 4 Partial correlation coefficient and significance test

\begin{tabular}{ccccccc}
\hline $\begin{array}{l}\text { Climatic } \\
\text { factors }\end{array}$ & $\begin{array}{l}\text { Extremely } \\
\text { Significant } \\
\text { Positive } \\
\text { Correlation }\end{array}$ & $\begin{array}{l}\text { Significant } \\
\text { Positive } \\
\text { Correlation }\end{array}$ & $\begin{array}{l}\text { Insignificant } \\
\text { Positive } \\
\text { Correlation }\end{array}$ & $\begin{array}{l}\text { Insignificant } \\
\text { Negative } \\
\text { Correlation }\end{array}$ & $\begin{array}{l}\text { Significant } \\
\text { Negative } \\
\text { Correlation }\end{array}$ & $\begin{array}{l}\text { Extremely } \\
\text { Significant }\end{array}$ \\
$\begin{array}{c}\text { Tempera } \\
\text { ture } \\
\text { Correlation }\end{array}$ \\
$\begin{array}{c}\text { Precipita } \\
\text { tion }\end{array}$ & $0.45 \%$ & $4.93 \%$ & $64.28 \%$ & $28.92 \%$ & $0.37 \%$ & $0.05 \%$ \\
\hline
\end{tabular}

337

338
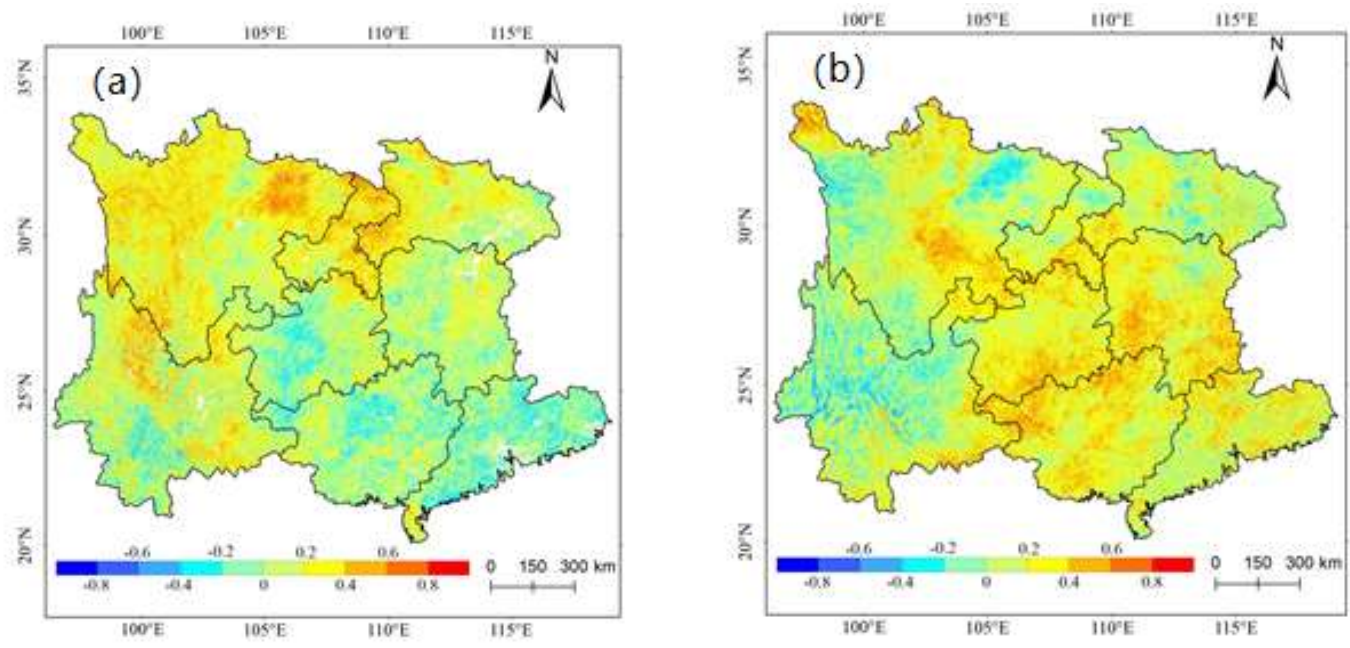

Fig.9 Partial correlation coefficient between annual mean temperature (a), precipitation (b) and annual mean WUE from 2001 to 2017

\subsection{The influence of vegetation on the WUE trend}

In addition to the effects of temperature and precipitation, the NDVI is an important factor

342 affecting the temporal and spatial distribution of WUE. In most areas, the annual average WUE and

343 the annual average NDVI were positively correlated, and only in the northeastern and southwestern

344 karst regions of southwestern China was there a certain degree of negative correlation. From 2001

345 to 2017 , the areas with a positive correlation between the annual average WUE and the average

346 annual NDVI in the southwest karst region accounted for $73.26 \%$ of the entire southwest karst

347 region, of which $14.84 \%$ of the regions passed the significance test, and $5.84 \%$ of the regions

348 reached a significance level of 0.01 . However, the average annual WUE and the annual average

349 NDVI were negatively correlated, and the area that passed the significance test accounted for only 
NDVI was beneficial in promoting the carbon sequestration of vegetation, and the increase in the NDVI may cause a decrease in soil evaporation, which in turn leads to a decrease in ET and an increase in WUE. Therefore, the average annual WUE was positively correlated with the average annual NDVI. For example, the vegetation coverage in central Sichuan and northeastern Yunnan was relatively low, so the increase in the NDVI contributed to the increase in WUE, and the annual average WUE and the annual average NDVI were extremely significantly positively correlated with a significance level of 0.01 .

\section{Discussion}

\subsection{Spatial and temporal variation analysis}

At this study's time scale, the WUE showed a downward trend in the southwest karst region, and at its spatial scale, high WUE values were mainly distributed in Yunnan Province, parts of Guangdong Province, northwestern Hubei Province, and northeastern Sichuan Province, while lowvalue areas were concentrated in western Sichuan Province. The study by Liu et al. (Liu et al., 2015) showed that WUE in southern China showed a downward trend from 2000 to 2011, which confirmed the results of this study. The results of this study were also consistent with those in arid and semiarid regions with a high ecosystem water use efficiency (Bai et al., 2020). Ding et al. (Ding et al., 2021) found that the annual average WUE in the karst area showed a significant increasing trend from 2001 to 2015. Their selected study area was part of the southwest karst area, which is different from this study area, which indicates that the karst area is widely distributed and has large temporal and spatial differences. Peng et al. (Peng et al., 2021) found that from 2000 to 2014, the 70\% water use efficiency of the study area showed an upward trend, and the water use efficiency of a few areas in northeastern Guizhou and southwestern Yunnan decreased, accounting for 35.4\% of the entire study area. This was mainly due to the different years of the studies. This study showed that WUE fluctuated before 2014 and had no obvious downward trend. After 2014, the water use efficiency in the southwest karst area decreased significantly. The comparison results showed that the WUE of different karst landform areas was quite different, which indicates that the geological and landform features of the karst area are complex, resulting in some differences in the WUE results. 


\subsection{The relative contribution rate of climate change and human activities to WUE}

\section{changes}

In this study, the effects of natural driving factors (precipitation, temperature) and anthropogenic driving factors on WUE were mainly explored. The results showed that the annual average WUE in most areas of Southwest China was positively correlated with the annual average temperature and negatively correlated with the annual average precipitation. In general, both climate change and human activities played an inhibitory role in the WUE changes in most areas of Southwest China, among which human activities played a leading role. The studies by Li et al. (Li et al., 2018; Xiao et al., 2013) and Xiao et al. (Li et al., 2018; Xiao et al., 2013) confirmed that WUE exhibited a positive sensitivity to temperature. Xue et al. (Xue et al., 2015b) found that WUE was positively correlated with precipitation, which may be due to the fact that their study area was nationwide, while the climate in karst areas is relatively humid and precipitation is not the main factor affecting vegetation growth. Under abundant rainfall conditions, soil erosion is more serious, which is not conducive to vegetation growth, resulting in a negative correlation between WUE and precipitation (Xue et al., 2015b). Liu et al. (Liu et al., 2015) suggested that WUE was positively correlated with drought. Huang et al. (Huang et al., 2017) suggested that the WUE in humid ecosystems showed both positive and negative response to drought. Various studies have shown that there is a complex relationship between WUE and precipitation. However, there is rocky desertification in the karst area of Southwest China, which often causes a coexistence of water shortages and heavy rains. The influence of climate characteristics such as precipitation and temperature on WUE is obviously differentiated.

In this study, human activities are considered to be negatively correlated with WUE in the southwestern karst region. Human activities are mainly divided into two parts. One part relates to restoration and ecological projects such as returning farmland to forests and grasslands. The other part relates to expansion. With the continuous acceleration of urbanization, the vegetation coverage rate has been reduced and the ecological balance has been destroyed. The results of Ding et al.'s (Ding et al., 2021) study showed that with the implementation of ecological restoration projects in the selected study area, WUE showed a significant upward trend. The results of this study showed 
that WUE was negatively correlated with human activities, which may be due to the rapid economic development, accelerated urbanization, and significant urban expansion in southwestern China from 2001 to 2017 (Liu et al., 2014). Due to the complexity of human activities, it is difficult to describe the relationship between them and WUE with a simple correlation analysis.

\subsection{Future perspectives and limitations}

Due to the numerous factors that affect the spatial change of WUE and the complicated process, there are still some problems and deficiencies in this research, which need to be further improved and discussed in future research. (1) Many different remote sensing satellite datasets were used in this study, and there was a problem of a temporal and spatial resolution mismatch between different data sources. Although this paper unified the data resolution of the research data, which reduced the impact of the data scale mismatch to a certain extent, it will inevitably still produce certain errors and have a certain influence on the research results. (2) There are many factors that affect the WUE of terrestrial ecosystems. In addition to the factors mentioned in this article, topography, soil type, relative humidity, extreme climate and other factors should be considered. In addition, some major national policies affect the WUE of vegetation in local areas. In follow-up research, these influencing factors should also be taken into consideration.

\section{Conclusion}

The ecosystem in the southwest karst region is fragile, natural areas are fragmented, and floods and droughts occur frequently, resulting in poor vegetation growth and a decline in vegetation coverage compared with other ecological regions. WUE is used as a measure of the response of terrestrial vegetation to water availability. We conducted a long-term series analysis of the water use efficiency in the southwestern karst area. The study showed that there were obvious spatial differences in the spatial distribution of WUE in the southwest karst region during 2001-2017, and the overall trend was decreasing. There were also certain differences in the WUE of different vegetation types, and the annual average WUE of most vegetation types showed a downward trend. In terms of influencing factors, the annual average WUE in most areas of southwest China was positively correlated with the annual average temperature and negatively correlated with the annual 
average precipitation. Human activities and climate change were both important factors affecting the WUE, and studies have shown that compared with climate factors, human activities play a dominant role in WUE changes in the southwest karst region. This study can provide important theoretical support for future research on ecological restoration in the southwest karst area.

\section{Acknowledgments}

This study was supported by the Beijing Natural Science Foundation (8192037), Key Research and Development Program of Guangxi (AB18050014), National Natural Science Foundation of China (Grant Nos. 41701391), and Yue Qi Yong Scholar Project, CUMTB.

\section{Ethics approval and consent to participate}

Not applicable

\section{Consent for publication}

450

$$
\text { Not applicable }
$$
corresponding author on reasonable request.

\section{Authors' contributions}

Xinyu Shi: methodology, writing, and formal analysis. Shuang Bai: coding and methodology.

Wei Chen: editing, data curation, investigation, and validation.

\section{Competing interests}




\section{References}

Ahmadi B, Ahmadalipour A, Tootle G, Moradkhani H. Remote Sensing of Water Use Efficiency and Terrestrial Drought Recovery across the Contiguous United States. Remote Sensing 2019; 11: 731.

Bai Y, Zha T, Bourque CP-A, Jia X, Ma J, Liu P, et al. Variation in ecosystem water use efficiency along a southwest-to-northeast aridity gradient in China. Ecological Indicators 2020; 110: 105932.

Baldocchi D. 'Breathing' of the terrestrial biosphere: lessons learned from a global network of carbon dioxide flux measurement systems. Australian Journal of Botany 2008; 56: 1-26.

Cao JH, Yuan DX, Tong LQ, Mallik A, Hui Y, Fen H. An Overview of Karst Ecosystem in Southwest China: Current State and Future Management. Journal of Resources and Ecology 2015; 6: 247-256.

Cheng L, Zhang L, Wang Y-P, Canadel1 JG, Chiew FH, Beringer J, et al. Recent increases in terrestrial carbon uptake at little cost to the water cycle. Nature Communications 2017; 8: 1-10.

Condon AG, Richards R, Rebetzke G, Farquhar G. Breeding for high wateruse efficiency. Journal of experimental botany 2004; 55: 2447-2460.

Ding Z, Liu Y, Wang L, Chen Y, Yu P, Ma M, et al. Effects and implications of ecological restoration projects on ecosystem water use efficiency in the karst region of Southwest China. Ecological Engineering 2021; 170: 106356.

Hofhans1 F, Chacón-Madrigal E, Fuchslueger L, Jenking D, Morera-Beita A, Plutzar C, et al. Climatic and edaphic controls over tropical forest diversity and vegetation carbon storage. Scientific reports 2020; 10: 1-11.

Huang L, He B, Han L, Liu J, Wang H, Chen Z. A global examination of the response of ecosystem water-use efficiency to drought based on MODIS data. Science of the Total Environment 2017; 601: 1097-1107.

Jiang WG, Yuan LH, Wang WJ, Cao R, Zhang Y, Shen W. Spatio-temporal analysis of vegetation variation in the Yellow River Basin. Ecological Indicators 2015; 51: 117-126.

Jiang Z, Lian Y, Qin X. Rocky desertification in Southwest China: Impacts, causes, and restoration. Earth-Science Reviews 2014a; 132: 1-12.

Jiang ZC, Lian YQ, Qin XQ. Rocky desertification in Southwest China: Impacts, causes, and restoration. Earth-Science Reviews 2014b; 132: 1-12.

Lakshmi Kumar TV, Rao K, Uma R, Barbosa H, Patnaik KVKRK, Jothi EP. On the relation of vegetation and southwest monsoon rainfall over Western Ghats, India. Natural Hazards 2016; 84: 425-436.

Li Y, Shi H, Zhou L, Eamus D, Huete A, Li L, et al. Disentangling climate and LAI effects on seasonal variability in water use efficiency across terrestrial ecosystems in China. Journal of Geophysical Research: Biogeosciences 2018; 123: 2429-2443.

Li Y, Zha T-S, Jia X, Qin S, Wu Y, Wang B. Photosynthetic characteristics 
of typical desert plant Artemisia ordosica in semiarid region. Chinese Journal of Ecology 2015; 34: 86-93.

Liu QH, Wang XH, Zhang YL, Zhang HM, Li L. Vegetation Degradation and Its Driving Factors in the Farming-Pastoral Ecotone over the Countries along Belt and Road Initiative. Sustainability 2019; 11: 1-16.

Liu Y, Huang X, Yang H, Zhong T. Environmental effects of land-use/cover change caused by urbanization and policies in Southwest China Karst area - A case study of Guiyang. Habitat International 2014; 44: 339-348.

Liu Y, Xiao J, Ju W, Zhou Y, Wang S, Wu X. Water use efficiency of China' s terrestrial ecosystems and responses to drought. Scientific reports 2015; 5: 1-12.

$\mathrm{Mu}$ Q, Zhao M, Running SW. Improvements to a MODIS global terrestrial evapotranspiration algorithm. Remote Sensing of Environment 2011; 115: 17811800 .

Mueller B, Seneviratne SI, Jimenez C, Corti T, Hirschi M, Balsamo G, et al. Evaluation of global observations-based evapotranspiration datasets and IPCC AR4 simulations. Geophysical Research Letters 2011; 38.

Peng D, Zhou Q, Wei X, Li H, Tang X, Yan W. Changes of water use efficiency in karst regions of Southwest China and its response to meteorological elements. Journal of Ecology 2021; 41: 9470-9480.

Peng S, Ding Y, Liu W, Li Z. 1 km monthly temperature and precipitation dataset for China from 1901 to 2017. Earth System Science Data 2019; 11: 1931-1946.

Qi X, Wang K, Zhang C. Effectiveness of ecological restoration projects in a karst region of southwest China assessed using vegetation succession mapping. Ecological Engineering 2013; 54: 245-253.

Qiu B, Xue Y, Fisher JB, Guo W, Berry JA, Zhang Y. Satellite chlorophyll fluorescence and soil moisture observations lead to advances in the predictive understanding of global terrestrial coupled carbon - water cycles. Global Biogeochemical Cycles 2018; 32: 360-375.

Tong S, Zhang J, Ha S, Lai Q, Ma Q. Dynamics of Fractional Vegetation Coverage and Its Relationship with Climate and Human Activities in Inner Mongolia, China. Remote Sensing 2016; 8: 776.

Verma M, Friedl MA, Richardson AD, Kiely G, Cescatti A, Law BE, et al. Remote sensing of annual terrestrial gross primary productivity from MODIS: an assessment using the FLUXNET La Thuile data set. Biogeosciences 2014; 11: 2185-2200.

Wang M, Chen H, Zhang W, Wang K. Soil nutrients and stoichiometric ratios as affected by land use and lithology at county scale in a karst area, southwest China. Science of The Total Environment 2018; 619-620: 1299-1307.

Wang S-J, Liu Q-M, Zhang D-F. Karst rocky desertification in southwestern China: geomorphology, landuse, impact and rehabilitation. Land Degradation \& Development 2004; 15: 115-121.

Wang Z, Wu R, Huang K, Qiu Y, Li Z, Lv Y, et al. Structure identification 
of a karst groundwater system based on high-resolution rainfall-hydrological response characteristics. Environmental Science and Pollution Research 2021: $1-14$.

Wu DH, Wu H, Zhao X, Zhou T, Tang BJ, Zhao W, et al. Evaluation of Spatiotemporal Variations of Global Fractional Vegetation Cover Based on GIMMS NDVI Data from 1982 to 2011. Remote Sensing 2014; 6: 4217-4239.

Xiao J, Sun G, Chen J, Chen H, Chen S, Dong G, et al. Carbon fluxes, evapotranspiration, and water use efficiency of terrestrial ecosystems in China. Agricultural and forest meteorology 2013; 182: 76-90.

Xu G, Zhang J, Li P, Li Z, Lu K, Wang X, et al. Vegetation restoration projects and their influence on runoff and sediment in China. Ecological Indicators 2018; 95: 233-241.

Xue B-L, Guo Q, Otto A, Xiao J, Tao S, Li L. Global patterns, trends, and drivers of water use efficiency from 2000 to 2013. Ecosphere 2015a; 6: art174.

Xue B-L, Guo Q, Otto A, Xiao J, Tao S, Li L. Global patterns, trends, and drivers of water use efficiency from 2000 to 2013. Ecosphere 2015b; 6: 1-18.

Zhao M, Running SW, Nemani RR. Sensitivity of Moderate Resolution Imaging Spectroradiometer (MODIS) terrestrial primary production to the accuracy of meteorological reanalyses. Journal of Geophysical Research 2006; 111.

Zhou Q, Luo Y, Zhou X, Cai M, Zhao C. Response of vegetation to water balance conditions at different time scales across the karst area of southwestern China-A remote sensing approach. Sci Total Environ 2018; 645: 460-470.

Zhu H, Lin A, Wang L, Xia Y, Zou L. Evaluation of MODIS Gross Primary Production across Multiple Biomes in China Using Eddy Covariance Flux Data. Remote Sensing 2016; 8. 


\section{Supplementary Files}

This is a list of supplementary files associated with this preprint. Click to download.

- Supplementarymeterials.docx 